\title{
Rapid Cytodiagnosis By Different Staining Techniques in Comparison with Conventional Stains in Thyroid Cytology
}

\author{
Veena Raja $^{1 *}$, Chinnaiya Subramaniyam Babu Rajendra Prasad ${ }^{2}$ and Lavanya Rajagopal ${ }^{1}$ \\ 'Department Of Pathology, SRM Medical College and Research Institite, SRM University, Kattankulathur, Chennai (India) \\ ${ }^{2}$ Department Of Pathology, Sri Deveraj Urs Medical College (R.L. Jalappa University), Kolar, Karnataka (India)
}

\begin{abstract}
Background: Fine needle aspiration cytology (FNAC) is a very important component of pre-operative / pre-treatment investigation in combination with clinical, radiological and other laboratory data. In spite of its advances and advantages, conventional FNAC fails to achieve a $100 \%$ accuracy. To improve the accuracy of FNAC, a supravital stained Toluidine blue wet mount (TBWM) preparation of the aspirate and Methylene blue/Eosin (M/E) stained smears are studied which will give additional information regarding the lesion on which FNAC is done.

Objective: To assess the diagnostic rapidity of the Toluidine blue wet mount preparation and Methylene blue/Eosin stain in FNAC and to compare the morphological features and results obtained from rapid stains with conventional PAP and H\&E techniques in FNAC.

Methods: The study was conducted on Fine needle aspirates from 100 patients presenting with thyroid swelling in R.L Jalappa hospital attached to Sri DevarajUrs Medical College, Kolar, Karnataka. TBWM, M/E stain, H\&E stain and Pap stain was done for all 100 cases. Time taken for each stain is assessed and the morphology of rapid stains were compared with the conventional stain. Quality index was calculated for all the stains.

Results: The rapidity of the stains was assessed for all four stains. Toluidine blue wet mount takes only 2 minutes for staining followed by Methylene blue/eosin which takes 5 minutes. M/E stain gave the same result as compared to the conventional stains [PAP and H\&E]. In TBWM there was difficulty in diagnosing few cases due to three dimensional clusters. The sensitivity and specificity of TBWM were $66 \%$ and $90 \%$ whereas for $\mathrm{M} / \mathrm{E}$ stain $98 \%$ and $100 \%$. The quality index of PAP stain, H\&E stain, M/E stain and TBWM were $0.85,0.81,0.71,0.66$.
\end{abstract}

Conclusion: Thus, both stains can be routinely undertaken as a supplementary procedure for conventional stains to improve the cellularity and to reduce the time taken for re-sampling.

Keywords: Toludine Blue Wet Mount, Methylene/Eosin, Rapid Cytodiagnosis, Quality Index

\section{Introduction}

Fine needle aspiration cytology (FNAC) technique has become more common and popular nowadays. Though it is not a substitute for conventional histopathology, it should be regarded as a very important component of pre-operative / pre-treatment investigation in combination with clinical, radiological and other laboratory data ${ }^{[1,2]}$ Since the majority of lumps are benign, FNAC plays a major role in making a diagnosis and planning appropriate management. ${ }^{[3,4]}$ The diagnostic accuracy of FNAC depends on adequacy and representativeness of sample and good cytomorphological detail without much artifactual distortion. Conventional FNAC has its own advantages and limitations, which are well known to any cytopathologist. In spite of its advances and advantages, conventional FNAC fails to achieve a $100 \%$ accuracy.This is partly because of,(i) A lack of sufficient cellularity in desmoplastic lesions.(ii) Wastage of aspirated cells when they stick to the hub and lumen of the needles, (iii) Morphological distortion produced when the cells are trapped in fibrin mesh, (iv) Distortion of fragile cells during smearing, (v) Loss of cell to cell and cell to stromal architecture ${ }^{[1,2]}$ Hence in an attempt to improve its accuracy, a supravital stained Toluidine blue wet mount (TBWM) preparation of the aspirate and Methylene blue/Eosin (M/E) stained smears are studied which will give additional information regarding the lesion on which FNAC is done. These supravital stains attains good definition of cell outline, cytoplasmic contents and nuclear details. Therefore this study is aimed at assessing the diagnostic rapidity of the Toluidine blue wet mount preparation and Methylene blue/Eosin stain in FNAC and to compare the morphological features and results obtained from rapid stains with conventional PAP and $\mathrm{H} \& \mathrm{E}$ techniques in FNAC.

\section{Materials and Methods}

The study was conducted on Fine needle aspirates from 100 patients presenting with thyroid swelling in R.L Jalappa hospital attached to Sri DevarajUrs Medical College, Kolar, Karnataka. Consent was taken from all the patients 
included in the study. Aspirates yielding very little material was excluded from the study.

\section{Toludine Blue Wet Mount Staining}

Step 1: A drop of fine needle aspirate is expressed on centre of slide

Step 2: In case of body cavity fluid cytology drop of fluid was placed in the center of slide if fluid was turbid or the fluid was centrifuged at $1500 \mathrm{rpm} / \mathrm{min}$ for 10 minutes. The supernatant fluid was discarded. Then a drop of well mixed sediment was placed in the center of slide.

Step 3: Add drop of $0.5 \%$ Toluidine blue stain

Step 4: Mix with needle

Step 5: Add a drop of diluted Eosin stain and mix well (optional)

Step 6: Cover with cover slip

Step 7: Wet mount was examined under microscope and cytomorphology was observed.

\section{Alternative Method of Preparation of Wet Mount}

This method was tried whenever aspirates were very scanty and adhered to hub of the needle. Under such condition it was very difficult to express the aspirate over the slides.

Step 1: A few drops of toluidine blue stain was aspirated using the same syringe and needle and rinsed.

Step 2: Then the stain mixed material was expressed in the center of slide.

Step 3: A drop of eosin solution was placed next to cell stain mixture and mixed well (optional)

Step 4: Cover with cover slip

Step 5: Wet mount was examined under microscope and cytomorphology was observed.

\section{Methylene Blue Alkaline/Eosin Staining}

Step 1: Air dry the smear

Step 2: Fix smear in 95\% methanol - $1 \mathrm{~min}$

Step 3: Wash in running tap water

Step 4: 1 Dip in 1\% eosin

Step 5: Wash in running tap water

Step 6: 1 dip in Loffler's methylene blue alkaline

Step 7: Wash in running tap water

Step 8: Air dry and mount with DPX

Toludine blue wet mount preparation, Methylene/Eosin stain, H\&E stain and Pap stain was done for all 100 cases.
Time taken for each stain is assessed and the morphology of rapid stains were compared with the conventional stain.

Assessment of Quality Index: The morphology of the cells was assessed using the following scoring system for all the four stains on all 100 cases using the following scoring system. [Table 1]

The maximum score for a single case, taking into account of all the four parameters, was 11. Thus, the maximum possible score in the study was calculated by multiplying the number of cases by 11 for each of four stains. The "Quality index" was obtained by finding out the ratio of actual score obtained to the maximum score possible.

Quality Index = Actual score obtained / maximum score possible. ${ }^{[5]}$

Statistical Analysis: We used the IBM SPSS Software (v.22) to perform the statistical analysis. Validation of rapid cytodiagnostic tests was done against the gold standard PAP and H\&E stains using tests like Sensitivity, Specificity, Positive predictive value and ROC curve. The $p$ value $\leq 0.05$ was considered significant.

\section{Results}

100 cases with good cellularity where all stains can be performed were chosen for the study. For each case four stains have been done and were analysed by two pathologists for the morphological features and for final diagnosis. Pathologists were blinded for final diagnosis.

Rapidity Assessment: The rapidity of the stains was assessed for all four stains. Toluidine blue wet mount takes only 2 minutes for staining followed by Methylene blue/ eosin which takes 5 minutes, H\&E stain with artificial drying takes 8 minutes and PAP stain with artificial drying takes 10 minutes.

Out of these 100 cases, M/E stain gave the same result as compared to the conventional stains [PAP and H\&E] except for 2 cases of Lymphocytic thyroiditis are diagnosed as Benign thyroid lesion. This is due to lymphocytes in these two cases were identified as naked follicular epithelial cells. In TBWM there was difficulty in identifying Hyperplastic goiter due to three dimensional clusters and difficulty in identifying Hurthle cells and fire flares. The next difficulty we faced is to diagnose Papillary carcinoma of thyroid as the nuclear grooves and inclusions are not well appreciated in TBWM. Thus the total number of concordant cases by TBWM is 73. [Table 2]

The sensitivity, specificity, positive predictive value and negative predictive value of TBWM and $\mathrm{M} / \mathrm{E}$ stain were $66 \%, 90 \%, 70 \%, 100 \%$ and $98 \%, 100 \%, 98 \%, 100 \%$ 
respectively. ROC Curve by comparing rapid stains with conventional stains are shown in figure 1.Area Under Curve for TBWM and $M / E$ were statistically significant with $p$ value $<0.05$. [Table: 3$]$

The morphology of the cells was assessed using the scoring system for all the four stains on all 100cases and the quality index were calculated[Table 4].The salient features of all four stains were shown in Table 5.

\section{Discussion}

FNAC plays a vital role as a rapid diagnostic technique because of its simplicity, cost effectiveness, early availability of results, accuracy and minimal invasion. Chandler foot et al (1958), Silverman et al (1989) Verma et al (1991), Chang et al (1993), yang et al (1995), Tsou et al (1997) experimented various rapid stains such as Neutral red Janus green, Diff Quik, rapid MGG, Liu's stain, ultra-fast

Table 1: The scoring system to assess Quality Index.

\begin{tabular}{|l|c|c|c|}
\hline SCORE & $\mathbf{1}$ & $\mathbf{2}$ & $\mathbf{3}$ \\
\hline SLIDE QUALITY Background & Hemorrhage/Necrosis & Clean & \\
\hline Overall staining & Bad & Moderately good & Good \\
\hline Cell morphology & Not preserved & Moderately preserved & Well preserved \\
\hline Nuclear characteristics & Smudgy chromatin & Moderately crisp chromatin & Crisp chromatin \\
\hline
\end{tabular}

Table 2: Distribution of concordant thyroid lesions based on stains.

\begin{tabular}{|l|c|c|c|}
\hline NATURE OF LESION & $\begin{array}{c}\text { CONVENTIONAL STAINS } \\
\text { (PAP AND H\&E) }\end{array}$ & METHYLENE/EOSIN & WET MOUNT \\
\hline Lymphocytic thyroiditis & 34 & 32 & 33 \\
\hline Colloid goiter & 19 & 19 & 19 \\
\hline Hyperplastic goitre & 17 & 17 & 4 \\
\hline Nodular goiter & 10 & 10 & 9 \\
\hline Benign thyroid lesion & 1 & 1 & - \\
\hline de-Quervains thyroiditis & 3 & 3 & 2 \\
\hline Acute suppurative thyroiditis & 2 & 2 & - \\
\hline Suspicious for malignancy & 1 & 1 & - \\
\hline Malignancy & 7 & 7 & 3 \\
Papillary carcinoma thyroid & 4 & 4 & 2 \\
Follicular neoplasm & 2 & 2 & $\mathbf{7 3}$ \\
Anaplastic carcinoma & $\mathbf{1 0 0}$ & $\mathbf{9 8}$ & \\
\hline TOTAL & & & \\
\hline
\end{tabular}

Table 3: Area Under Curve.

\begin{tabular}{|c|c|c|c|c|c|}
\hline \multirow{2}{*}{ Test Result Variable(s) } & \multirow{2}{*}{ Area } & \multirow{2}{*}{ Std. Error ${ }^{a}$} & \multirow{2}{*}{ p value ${ }^{b}$} & \multicolumn{2}{|c|}{ Asymptotic $95 \%$ Confidence Interva } \\
\hline & & & & Lower bound & Upper bound \\
\hline WM & 0.679 & 0.092 & $<0.033^{*}$ & 0.499 & 0.858 \\
\hline $\mathrm{M} / \mathrm{E}$ & 1.000 & 0.000 & $<.0001^{*}$ & 1.000 & 1.000 \\
\hline
\end{tabular}

Table 4: The results of estimating the efficacy of four stains $(n=100)$.

\begin{tabular}{|c|c|c|c|c|c|c|c|c|}
\hline PARAMETER & PAP & SCORE & H\&E & SCORE & $M / E$ & SCORE & WM & SCORE \\
\hline \multicolumn{9}{|c|}{ BACKGROUND } \\
\hline $\begin{array}{l}\text { Hemorrhage/ } \\
\text { necrosis }\end{array}$ & 10 & 10 & 10 & 10 & 11 & 11 & 12 & 12 \\
\hline Clean & 90 & 180 & 90 & 180 & 89 & 178 & 88 & 176 \\
\hline \multicolumn{9}{|c|}{ OVERALL STAINING } \\
\hline Bad & 11 & 11 & 15 & 15 & 21 & 21 & 39 & 39 \\
\hline Moderately good & 18 & 36 & 28 & 56 & 61 & 122 & 52 & 104 \\
\hline
\end{tabular}




\begin{tabular}{|c|c|c|c|c|c|c|c|c|}
\hline PARAMETER & PAP & SCORE & H\&E & SCORE & M/E & SCORE & WM & SCORE \\
\hline Good & 71 & 213 & 57 & 171 & 18 & 54 & 9 & 27 \\
\hline \multicolumn{9}{|c|}{ CELL MORPHOLOGY } \\
\hline Not preserved & 6 & 6 & 6 & 6 & 11 & 11 & 15 & 15 \\
\hline Moderately preserved & 32 & 64 & 38 & 76 & 63 & 126 & 72 & 144 \\
\hline $\begin{array}{l}\text { Well preserved and } \\
\text { crisp }\end{array}$ & 62 & 186 & 56 & 168 & 26 & 78 & 13 & 39 \\
\hline \multicolumn{9}{|c|}{ NUCLEAR CHARACTERISTICS } \\
\hline Smudgy chromatin & 15 & 15 & 16 & 16 & 28 & 28 & 34 & 34 \\
\hline $\begin{array}{l}\text { Moderately crisp } \\
\text { chromatin }\end{array}$ & 37 & 74 & 51 & 102 & 56 & 112 & 57 & 114 \\
\hline Crisp chromatin & 48 & 144 & 33 & 99 & 16 & 48 & 9 & 27 \\
\hline Actual score obtained & \multicolumn{2}{|c|}{939} & \multicolumn{2}{|c|}{899} & \multicolumn{2}{|c|}{789} & \multicolumn{2}{|c|}{731} \\
\hline $\begin{array}{l}\text { Maximum score } \\
\text { possible }\end{array}$ & \multicolumn{2}{|c|}{1100} & \multicolumn{2}{|c|}{1100} & \multicolumn{2}{|c|}{1100} & \multicolumn{2}{|c|}{1100} \\
\hline QUALITY INDEX & \multicolumn{2}{|c|}{0.85} & \multicolumn{2}{|c|}{0.81} & \multicolumn{2}{|c|}{0.71} & \multicolumn{2}{|c|}{0.66} \\
\hline
\end{tabular}

Table 5: The salient features of all four stains.

\begin{tabular}{|l|l|l|l|l|}
\hline Feeatures & pap & H\&E & m/e & TBWM \\
\hline Smearingtechnique & Important & Important & Important & Nil \\
\hline Fixation & Immediate fixation & Immediate fixation & Air drying followed by fixation & Nil \\
\hline Artifacts & Delay in fixation & Delay in fixation & Nil & Air bubbles \\
\hline Cell loss & Due to wet fixation & Due to wet fixation & Minimal & Minimal \\
\hline Cell size & $\begin{array}{l}\text { Decreased, due to } \\
\text { immediate fixation }\end{array}$ & $\begin{array}{l}\text { Decreased, due to } \\
\text { immediate fixation }\end{array}$ & Increased due to air drying & Increased \\
\hline Cytoplasm & Well appreciated & Well appreciated & Moderately appreciated & Poor \\
\hline Nucleus & Excellent & Excellent & Excellent & Moderately good \\
\hline Nucleolus & Distinct & Excellent & Excellent & $\begin{array}{l}\text { Excellent, appears } \\
\text { immediately }\end{array}$ \\
\hline Tissue fragment & Good & Good & Moderate & Moderate \\
\hline Advantage & Crisp Nuclear details & $\begin{array}{l}\text { Very good nuclear } \\
\text { details, similar to PAP }\end{array}$ & $\begin{array}{l}\text { Immediate assessment, Good } \\
\text { nuclear details }\end{array}$ & $\begin{array}{l}\text { Obtain material from } \\
\text { needle hub }\end{array}$ \\
\hline Disadvantage & $\begin{array}{l}\text { Cell loss due to wet } \\
\text { fixation }\end{array}$ & $\begin{array}{l}\text { Cell loss due to wet } \\
\text { fixation }\end{array}$ & $\begin{array}{l}\text { Increased nuclear size due to } \\
\text { drying }\end{array}$ & $\begin{array}{l}\text { Three dimensional } \\
\text { clusters masking the } \\
\text { cellular details }\end{array}$ \\
\hline Slide preservation & Preserved & Preserved & Preserved & Cannot be preserved \\
\hline Cost & Expensive & Expensive & Cost effective & Cost effective \\
\hline Rapidity & 10 minutes & 8 minutes & 5 minutes & minutes \\
\hline
\end{tabular}

Table 6: Comparison of diagnostic accuracy of rapid stain with other studies.

\begin{tabular}{|l|c|c|c|}
\hline AUTHORS & YEAR OF THE STUDY & RAPID STAIN USED & DIAGNOSTIC ACCURACY \\
\hline Chandler foot et al. $^{6}$ & 1958 & Neutral red Janus green stain & $80 \%$ \\
\hline Silverman et al. $^{7}$ & 1989 & Diff-quik stain & $96 \%$ \\
\hline Kusumverma et al. $^{8}$ & 1991 & Rapid MGG stain & $97 \%$ \\
\hline Chang et al. $^{9}$ & 1993 & Liu's stain $^{\prime}$ & $94.9 \%$ \\
\hline Tsou et al. $^{11}$ & 1997 & Riu's stain & $93.5 \%$ \\
\hline Joy MP et al. $^{3}$ & 2003 & Toludine blue stain & $98.54 \%$ \\
\hline Sumathy C et al. & \\
\hline SumathiS et all. & Toludine blue wet mount & $89 \%$ \\
\hline Present study & 2012 & Toludine blue wet mount & $87 \%$ \\
\hline Present study & 2013 & Toludine blue wet mount & $76 \%$ \\
\hline
\end{tabular}




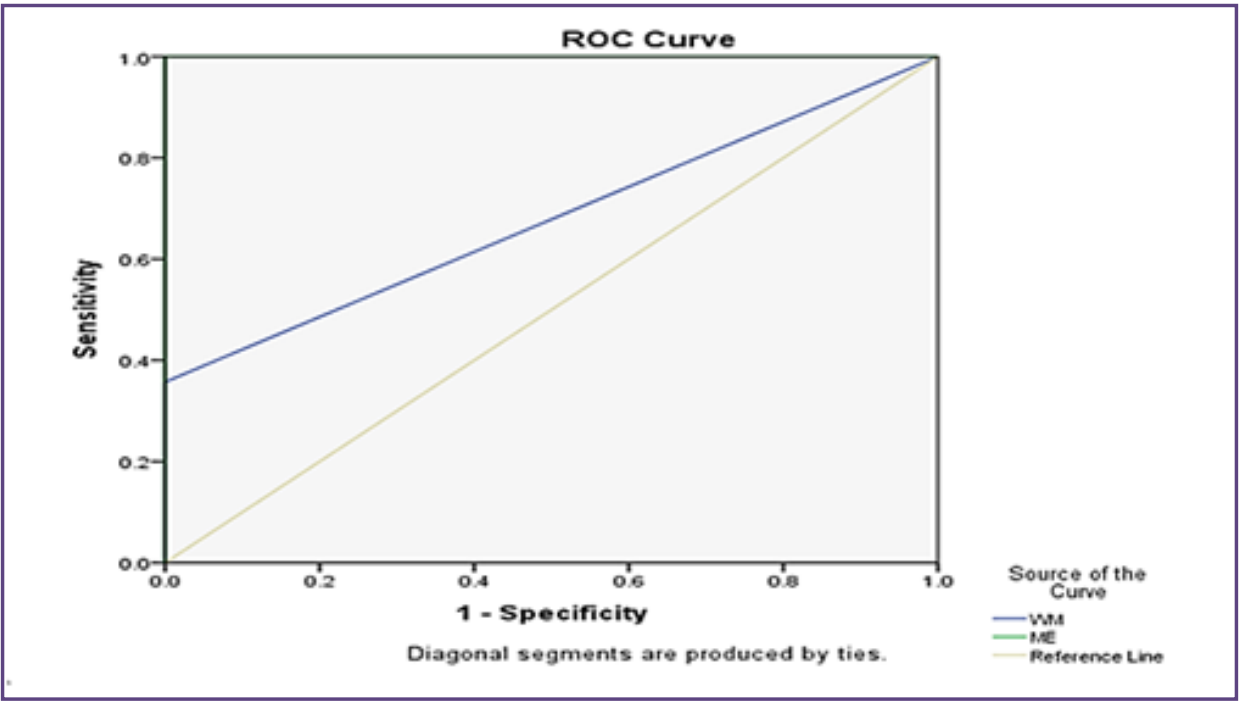

Fig. 1: ROC curve by comparing M/E and TBWM with conventional stains [PAP and H\&E].

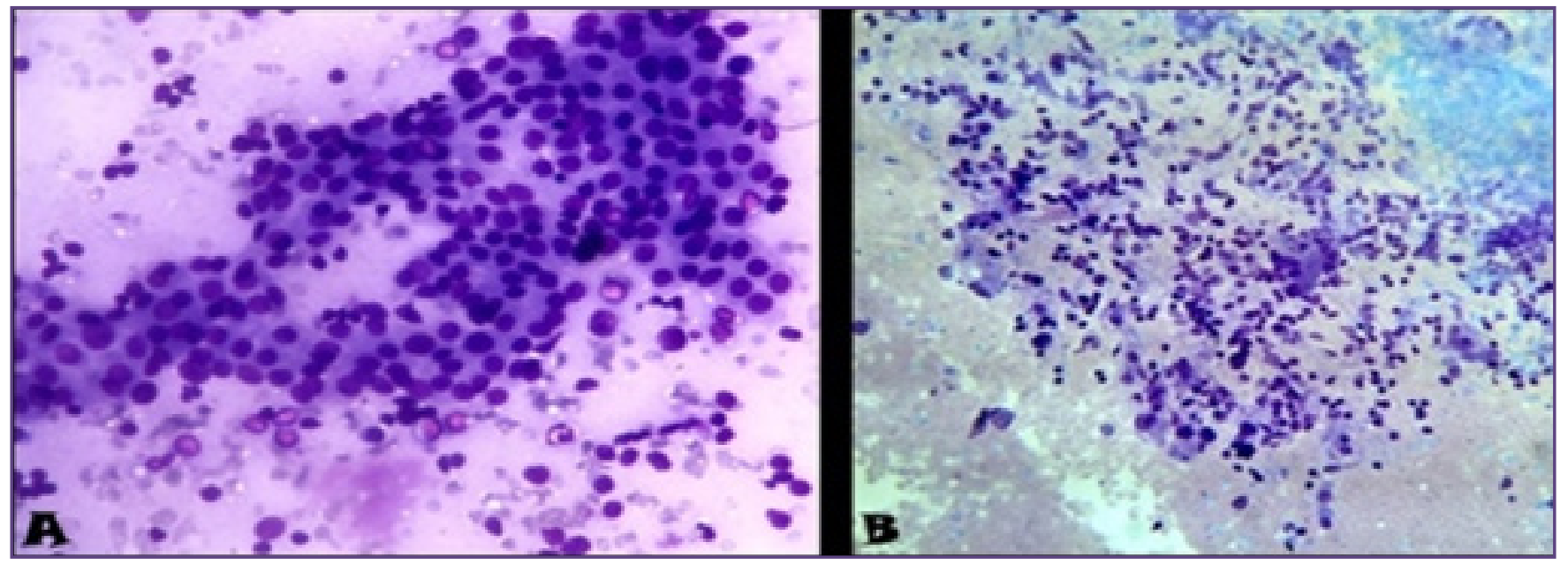

Fig. 2: Lymphocytic thyroiditis: A - M/E, B - TBWM.

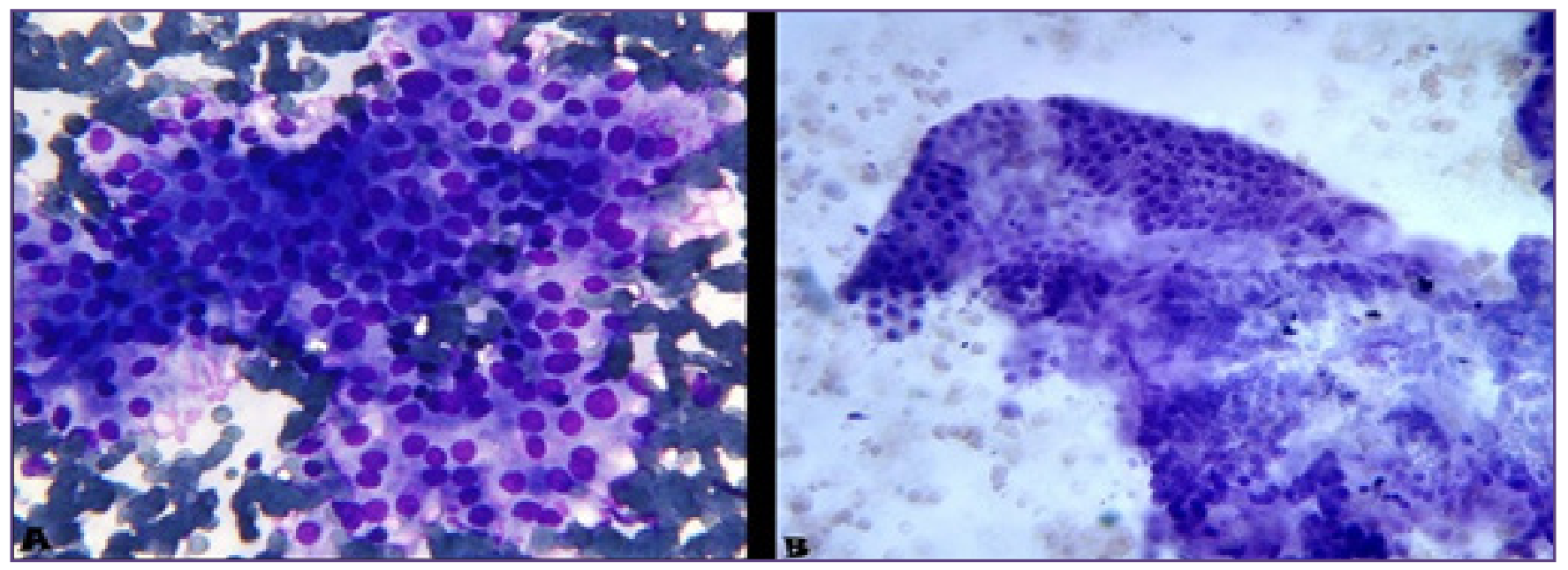

Fig. 3: Hyperplastic goiter: A - M/E, B - TBWM. 


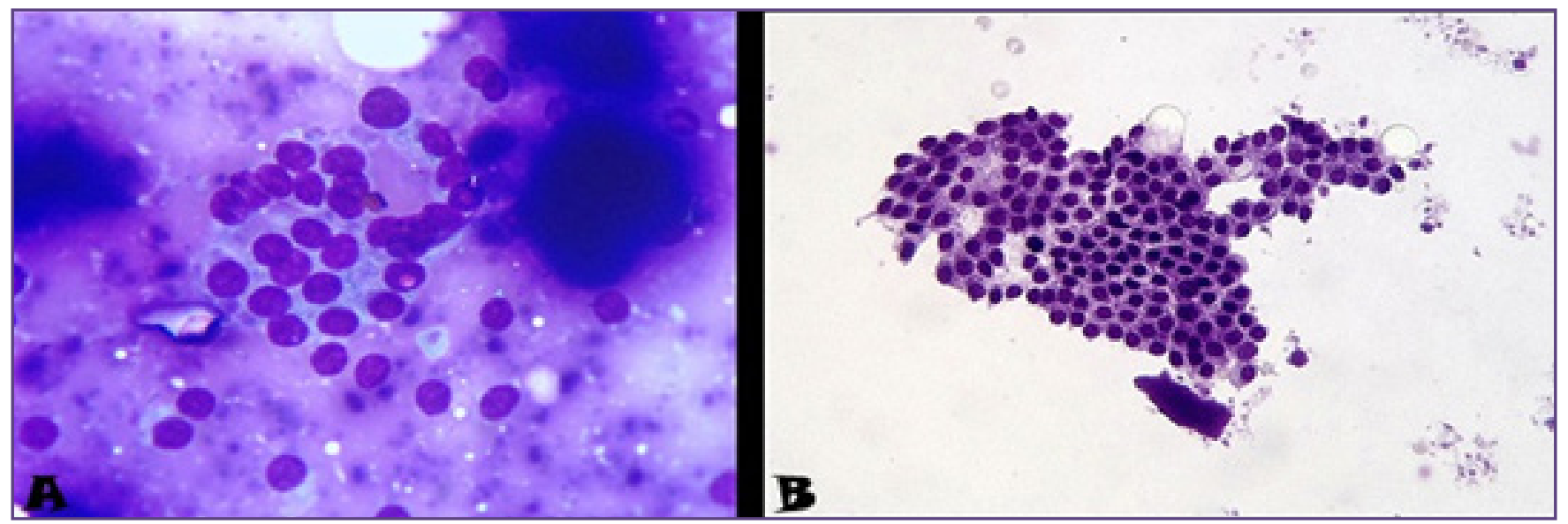

Fig. 4: Papillary thyroid carcinoma: A - M/E, B - TBWM.

PAP, Riu's stain respectively for immediate diagnosis. ${ }^{[6-11]}$ This work was inspired by the earlier work of Joy, M.P. et al in 2003 where they applied toluidine blue as a rapid stain for quick diagnosis of ultrasound guided aspiration cytology. ${ }^{[3]}$

The rapidity of the stains was assessed and found that toluidine blue wet mount stains in 2 minutes followed by methylene blue/eosin in 5 minutes. Rapid staining technique has an advantage of assessing the cellularity and adequacy of the material within few minutes and the reaspiration can be performed immediately. This will be of much help in USG or CT guided FNAC.

Caya et al in 1984 reported that false negative reports were resulted from unrepresentative aspirates. False negative aspirates may include normal or reactive elements but necrotic material is an additional source of error. ${ }^{[12,13]}$ This problem of sampling error cannot be eliminated entirely in FNAC but it is found reduced by rapid cytology assessment. This sampling error is reduced in our study by simultaneously doing rapid wet mount study. Cagle et al., in 1993 reported that inadequate sampling was solely responsible for $10 \%$ false negative report in lung FNAC. ${ }^{[14]}$ In our study the needle and hub are rinsed with toluidine blue stain, which effectively washes all the cells collected in the lumen yielding an improved cellularity.

Degenerated cells and neoplastic cells are more fragile and distorted easily during smearing which created confusion in diagnosis. Trapping of cells within fibrin meshwork also distorted the morphology of cell. Since cytomorphology forms the basis for the cytodiagnosis, artifactual morphological distortion influences the diagnostic accuracy of FNAC. ${ }^{[7]}$ This smearing artifact is avoided in our study since we used wet mount preparations as one of the rapid stain. The disadvantage of this wet mount technique was three dimensional clusters of cells which reduces the diagnostic accuracy in our study.

One of the most important features in cytodiagnosis is the morphology of the nucleus. ${ }^{[12]}$ The advantage of this supravital stain is that the cell structure is well preserved with toluidine blue stain. ${ }^{[15]}$ Supravital stain has a high affinity for DNA and hence absorbed rapidly into the nucleus. As the dysplastic and anaplastic cells contain more nucleic acid, the nuclear stains of tumor cells are very prominent with toluidine blue. ${ }^{[16]}$ Another advantage is the postfixation after air-drying facilitates chromatin staining in $\mathrm{M} / \mathrm{E}$ stain which will improve the diagnostic accuracy in malignant cases.

Colloid stains blue to purple and form thin membrane like coat often with folds and cracks. ${ }^{[17]}$ In our study thick colloid stains as patchy dark blue colour material and thin colloid stains as granular purple material in both $\mathrm{M} / \mathrm{E}$ and TBWM. The cyst macrophages are also well appreciated in both the stains. There was difficulty in identifying lymphocytic thyroiditis in $\mathrm{M} / \mathrm{E}$ due to lymphocytes in two cases were identified as naked follicular epithelial cells[Fig 2].The major discrepancy in TBWM was found in the cases of hyperplastic goitre, as the fire flares are not well appreciated. There was no difficulty faced in diagnosing hyperplastic goitre in $\mathrm{M} / \mathrm{E}$ [Fig 3].In cases of follicular neoplasm the arrangement of the cells in follicular pattern and the nuclear details was well appreciated in both $\mathrm{M} / \mathrm{E}$ and TBWM. Anaplastic carcinoma of thyroid shows pleomorphic cells with prominent nucleoli and multinucleated cells which was well appreciated in both the rapid stains.Smear from papillary carcinoma of thyroid shows sheets of cell with enlarged ovoid nucleus, granular chromatin and prominent nucleoli with cytoplasmic inclusions and nuclear grooves. In our study papillary sheets of follicular cells showed nucleus with small prominent basophilic nucleoli and some 
with nuclear inclusion in $\mathrm{M} / \mathrm{E}$ stain. But in TBWM the inclusions could not be identified [Fig 4]. The diagnostic accuracy of rapid stains were compared with other studies and shown in table 6.

The slides of TBWM could not be preserved since the cells were not fixed and should be photographed immediately. This is the major disadvantage of this stain. But it can be preserved for few hours, by sealing the cover slip by applying melted Vaseline or DPX. By this improvement the cytomorphology can be retained for a period of 2 to 3 hours without any morphological distortion and the quick drying of wet mount can also be prevented.

In most of the cases the material gets stuck in needle hub which is very difficult to obtain on the slide. This drawback was overcome by TBWM, where the toluidine blue is directly aspirated on the same needle used for FNAC and the material is expressed on the slide. This technique helps in obtaining the overall material from the needle and will improve the cellularity and helps in supplementing the conventional stains.

$\mathrm{M} / \mathrm{E}$ stain helps in assessing the cellularity within few minutes which will guide us whether to proceed with the staining or to do re-aspiration. This method helps in reducing the time consumption in cases of USG guided FNAC and in intra operative cytodiagnosis.

\section{Conclusion}

Thus Toluidine blue wet mount and Methylene blue/Eosin stain can be used as a rapid diagnostic test. It is also used to assess adequacy of sample especially for deep seated lesions and in USG guided FNAC. It can be used for intra operative cytodiagnosis as an adjunct to frozen section diagnosis. Thus, both stains can be routinely undertaken as a supplementary procedure for conventional stains to improve the cellularity and to reduce the time taken for re-sampling. This work gives a new dimension to the art of FNAC and also opens a new door for further researches in this regard.

\section{References}

1. Sumathi S, Mrinalini VR. Supravital stained wet film study of fine needle aspirates: A reliable supplementary diagnostic procedure. Clin Cancer Investig J 2012;1:135-39.

2. Sumathy C, Durai SJ, Swaminathan K, Vallimanalan S, Munavarah SA. Supravital stained rapid wet mount preparation of fine needle aspirates-A cytomorphological study. TEJMS 2012;3:62-66.
3. Joy MP, Iyer VK, Aron M, Kapila K, Verma K. Rapid staining using toluidine blue: A reliable method for quick diagnosis in ultrasound guided aspiration cytology. Indian J PatholMicrobiol 2003;46:589-92.

4. Erkilic S, Kocer NE. Diagnostic accuracy of toluidine blue stained wet films in effusion cytology. ActaCytol 2006;50:407-9.

5. Idris AAA, Hussain MS. Comparison of the efficacy of three stains used for the detection of cytological changes in Sudanese females with breast lumps. Sudanese J Pub Health 2009;4:275-77.

6. Foot CN, Nelson D, Quist H. Supravital staining of sediments of serous effusions, a simple technique for Rapid Cytological diagnosis. Cancer 1958;11:151-157.

7. Silverman JF, Finley JL, O'Brien KF, Dabbs DJ, Park HK, Larkin EW, et al. Diagnostic accuracy and role of immediate interpretation of fine needle aspiration biopsy specimen from various sites. ActaCytol1989;33:791-796.

8. Verma K, Tiwari MC, Agarwal J, Kapila K. Diagnostic accuracy of immediate interpretation of fine needle aspiration. Indian J Med Res 1991;94:197-199.

9. Chang MC, Chan RD, Ho WL. Intra operative cytology, the use of Liu's stain for immediate diagnosis. Zhonghua Yi XueZaZhi (Taipei) 1993;51:368-375.

10. Yang GC, Alvaraz 11. Ultra fastpapanicolaou stain. An alternative preparation for fine needle aspiration cytology. ActaCytol1995;39:55-60.

11. Tsou MH, Lin HH, Ko JS. Riu's Stain and the cytologic diagnosis of thyroid fine needle aspiration a single cancer center experience. DiagnCytopathol1997;16:543-547.

12. Caya JG, Clower LJ, Wollenberg NJ, Tiev TM. Transthoracoc fine needle aspiration cytology, Analysis of 82 patients with detailed verification criteria and evaluation of false negative cases. Am J ClinPathol1984;82:100-103.

13. Winning AJ, Seed MJ, Husain WA, Metaxas OAN. Interpretation of Negative results in fine needle aspiration of discrete pulmonary lesions. Thorax 1986;41:875-9.

14. Cagle PT, Kovach M. Ramzy I. Causes of false results in transthoracic fine needle aspirates. ActaCytol1993;37:16-20.

15. David J, Henry CK, Feider, Splittgerber GF. Toluidine blue dye as a breast localization marker. Am J Roentqenol1989;153:261-263.

16. Dudgeon LS, Patrick CV. A new method for the rapid microscopical diagnosis of tumors. Br J Surg1927;15:250-261.

17. Orell SR. Fine needle aspiration cytology. 5th ed. New Delhi: Elsevier; 2013.

*Corresponding author:

Dr. Veena Raja, No. 1, Arasamara Pallam Street, Krishnapuram, Ambur - 635802, Vellore District, Tamilnadu, (India)

Phone: +91 9600385030

Email: drveenaraja88@gmail.com

Date of Submission : 28.07.2017

Date of Acceptance : 12.08.2017

Financial or other Competing Interests: None.

Date of Publication : 22.12.2017 